\title{
Analysis of Korea Buncheong ware by Bunjang (White slip) technique
}

\author{
Hae-Jin Kim \\ Division of Crafts Design \\ Kongju National University, Kongju City, Chungnam, Korea \\ Hae-Sin Ro \\ Division of Crafts Design \\ Kongju National University, Kongju City, Chungnam, Korea \\ Won-Seok kim \\ Division of Crafts Design \\ Kongju National University, Kongju City, Chungnam, Korea
}

\begin{abstract}
Bunjang is one of the oldest and the best known traditional pottery technique in the Korean ceramic history, which still remains popular today. This research designed for understanding origin and changing history of Bunjang, Birth of Buncheong ware, Definition of Buncheong ware, process of Bunjang, Texture of clay, Glaze, and firing, form, decorative pattern, technique of Bunjang, CIngredients and Raw material: Proportion of raw materials. Bujang technique that can be called beginning of modern ceramic art in Korea, in this research, we can recognize the aesthetic value of Bujang and how modern ceramic artists are going to take advantage of Bunjang technique for their own use.
\end{abstract}

Key words: Bunjang, Buncheong, Tradition, Decoration

\section{INSTRUCTION}

Bunjang is one of the oldest and best known traditional pottery techniques in the Korean ceramic history, which still remains popular today. Bunjang is the special term referred to as white slip or engobe of the western cultures, which also shares similar characteristics of terra sigillata and majolica.

Throughout history, many different types of slips and slip application techniques have been developed for use by potters around the globe; Albany slip in some American Indian cultures and multi-color slips in the Incan culture of Peru, as well as slip decorations of the Trahuanaco, also of Peru, are some of the similar slip techniques to name a few. In spite of differences in raw materials used, purpose of its usage and cultural origins, these slips obviously share a certain degree of similarity to the Korean Bunjang technique. The traditional Bunjang is still considered as a commonly used technique by numerous contemporary Korean potters and ceramicists.

This paper will analyze the use of Bunjang techniques throughout different stages of Korean ceramic history, especially looking at the 15th century. "Buncheong ware"

\footnotetext{
* Corresponding author,Email : artceramic@kongju.ac.kr Manuscript received Apr. 30, 2012; revised May 07, 2013; accepted May 17, 2013
}

(known to be Buncheong pottery or ceramics that used Bunjang technique) is the type of ceramics that best represents the unique beauty of Korean ceramics. In appearance, Buncheong ware is relatively less decorative compared to Koryo celadon ware with sophisticated Sanggam technique. However, the unique beauty of Buncheong ware has been reviewed and reevaluated by contemporary Korean ceramics community. The simple and practical appearance just suitable for everyday usage are rediscovered and looked in with more detail.

\section{ORIGIN AND CHANGING HISTORY OF BUNJANG}

The history of Bunjang or the use of slip goes as far back as B.C. 5000 that is when the first appearance of colored slip was found near Harappa in India, followed by the Egyptian and Mesopotamian potteries with slip decoration around B.C. 4300. Also, black, red, or white slip patterns were also discovered in the East Asian potteries produced around B.C 3000.

In the West, the use of terra sigillata in the ancient Roman potteries and Greek blackware are the examples of classic slip ware. Terra sigillata is clay in liquid state which, after firing, creates high density and glossy surface with colors such as brown, red or ocher, yet it is not defined as a glaze as such. Owing to its prominent features of shinny red surface resulted 
from the use of terra sigillata, the term itself had become the immediate symbol and specification of mass-produced potteries and ceramics of the Roman era. For example, the Roman Castor ware displayed Keltic style drawings as surface decoration using white slip application technique known as 'Barbotine' while iron-contained slip was changed in reduction firing process.[1]

Silhouette painting is another distinctive slip application technique found in the Athens blackware produced around B.C. 6 century.

The purpose of slip application on the body, Bunjang, was to create a gloss finish on surface; once the raw materials were mixed and filtered to be made into slip with extra fine, ironcontained particles, and applied in thin layer of coat on a body surface. The slip was fired to the point of vitrification. Due to oxidized iron in the material, burgundy or buff or brown in rare case were yielded after firing.

Another noticeable slip application technique called 'Sgraffito' was found in potteries made in the 11th century in the entire region of the Middle East. The surface of the slip was scratched and combed to leave patterned marks revealing bare, reddish brown body underneath. Transparent glaze was usually applied after bisque firing. Sgraffito is known to be the origin of the Italian majolica.

A great number of American Indian earthenware was produced using clay whose physical qualities were similar to that of the clay used in Albany slip. Usually the earthenware was burnished with wood, pebble, or steel before firing in order to produce polished surface instead of being glazed.

In the Korean ceramic history, early Bunjang technique was found in the red (Fig.1)and black slip wares of the Bronze age. As seen, red slip had been used to cover up the roughness of clay body as well as for decorative purpose.

From the mid to the end of 12th century Bunjang technique was gradually changed its form of application; mere covering of slip on the entire surface was replaced and disappeared as the celadon inlaid decoration(Fig.2) came in to use with more elaborate and detailed handling, which clearly marked itself as the unique national beauty of Koryo Dynasty. As Koryo Dynasty ended towards the end of the 14th century, there was a rapid decline in the production of Koryo celadon that the elaborate handling involved in its making process was completely lost (Fig.3), and therefore led to an end in its production.

With the beginning of the Chosun Dynasty, Inhwa(stamping technique) technique apparently replaced the Koryo celadon inlaid decoration, and this eventually developed to become "filling-in" Bunjang on almost the whole surface of the body. The continual practice and application of this particular method led to the flourish of Chosun Buncheong ware (Fig.4) (Fig.5) in the 15 th century.[2]

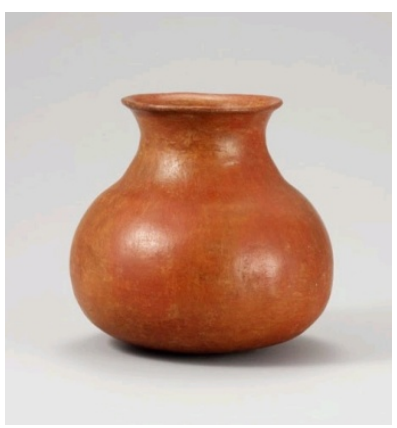

Fig.1. Burnished red earthware

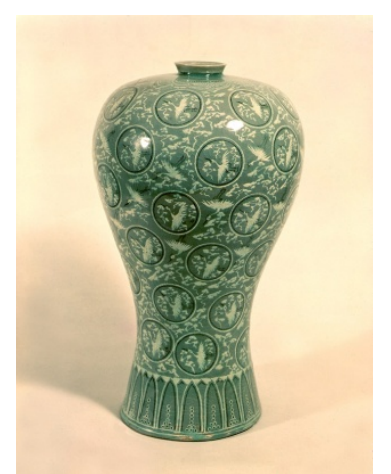

Fig.2. Goryeo lnlaid bottle with cloud and crane pattern

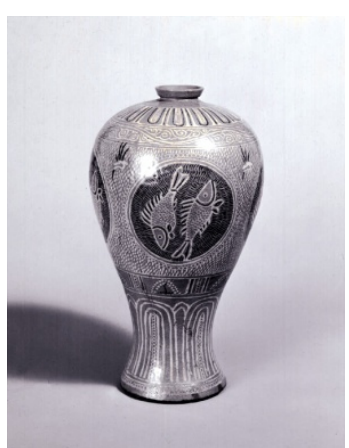

Fig. 3. Buncheong lnlaid bottle with fish and crane pattern

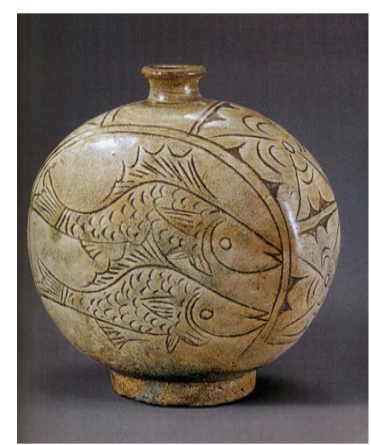

Fig. 4. Buncheong ware with lnlaid design

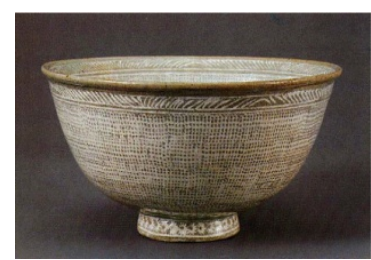

Fig. 5. Buncheong ware with lnlaid design 


\section{DEFINITION OF BUNCHEONG WARE AND BIRTH OF BUNCHEONG WARE}

Buncheong ware is defined as pottery that is made with ironrich clay decorated with white slip. After bisque fired, transparent glaze is to be applied and then fired in reduction or semi-oxidation

-white slip to be applied on gray or dark gray clay body, pale blue semi-transparent glazed

-using secondary (transported) clay to build a form and natural feldspar glaze applied

Buncheong ware was originated between the end of Koryo Dynasty and early Chosun Dynasty. Buncheong ware production was at its peak when the Chosun Dynasty was politically and socially settled around the 15th century. It was noted that the transition of the pottery as a whole, was clear at the time of King Sejong's reign; that was when Buncheong ware was replaced of Koryo Sanggam celadon, which almost disappeared then. At the end of 15 th century, the central government began direct supervision of the national Buncheong production, supporting and building the Royal kilns around Gwangju, Kyonggi-do. During the 16th century however, Buncheong production and operation were reduced to small scale and gradually disappeared after the mid-16th century. The history of Buncheong ware production only lasted 200 years.[3]

The major characteristics of Buncheong ware came from various decoration techniques of white clay (or slip) Bunjang and almost semi-abstract, bald, and energetic patterns and designs, that earned wide popularity from the Royals to common people.

Buncheong ware only had 200 years of history before the appearance of Chosun white porcelain, yet the unique aesthetics achieved in Buncheong ware is still the center of attention in the Korean ceramic community today. Buncheong ware have become a fascinating subject for many ceramic professionals, artists and history academics who are trying to discover historical and cultural values that Buncheong ware shed.

It may seem to be hard to sense the kind of serene elegance or sophistication from Buncheong ware, that are easily found in Koryo celadon(Fig.6) or White Stoneware(Fig.7) at first sight. For some viewers, most Chosun Buncheong ware may give an impression of unfinished look due to the lack of articulation in terms of handling and bald and child-play like patterns. This is the unique characteristics accomplished in traditional Buncheong ware, and what makes Buncheong ware distinguishable from celadon or white stoneware.[4]

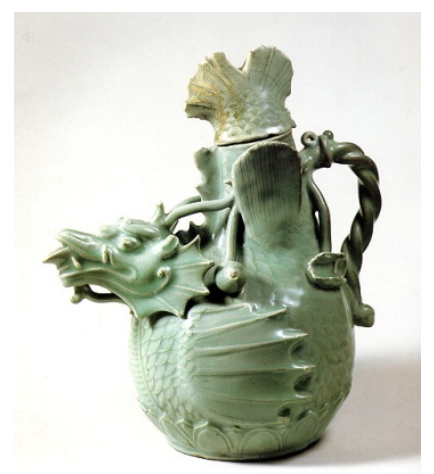

Fig. 6. Goryeo celadon bottle with dragon pattern

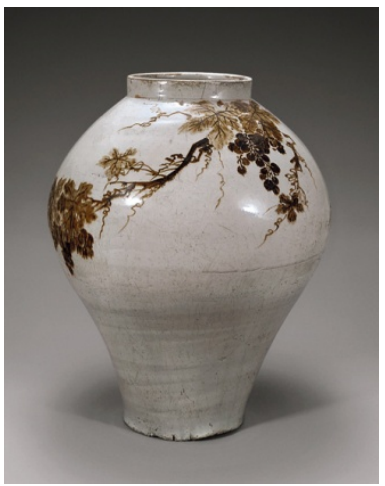

Fig. 7. Porcelain painted in underglaze iron-brown

\section{CLAY, GLAZE, AND FIRING METHODS}

Buncheong ware is the pottery made using 'secondary clay' and transparent glaze is applied on the surface. Secondary clay is also called 'transported clay' or 'deposited clay' because the clay has been deposited and transported from its origin of formation. Original rocks go through natural weathering processes like wind or rain, which are eventually broken, crushed and decomposed into fine particles, and transported by geological force. During the transporting process, impurities in clay particles go through natural filtration process which then leads particles with similar quality and size to be deposited to form secondary clay. Usually the particle size of secondary clay is smaller and finer, with excellent plasticity. Also due to the high content of Iron or copper that are composited throughout transporting and depositing processes, the color of clay body after firing is usually expected to be dark and intense.

The typical glaze used on Buncheong ware is usually transparent with a tint of pale blue or gray-white. It is usual to find that the surface color of Buncheong ware comes out to be grayish blue since a thin coat of glaze is applied that the body color is revealed underneath the glazed surface. Early Buncheong ware was ashy-straw or dark green in its color due to either reduced or oxidized firing condition. However as firing condition was settled to reduction, the color of most Buncheong ware was fixed with pale grayish blue.[5] 


\section{THE FORMS}

Buncheong ware was made for daily use by a range of different social classes from the Royal family, upper class to common people. Due to high demand of Buncheong ware, there existed many different forms of Buncheong ware. The shapes and forms of Buncheong ware were borrowed from Koryo celadon wares including Maebyong, bowl, bottle, flask, dish, cup, covered bowl, teapot, liquid container, jar, etc. Also various types of ritual vessels, stationery items and even grave stones were mass produced using Buncheong. The variety, practicality, productivity and stability of the form itself were noticeable advantages of Buncheong ware as those qualities accorded with pragmatic and utilitarian philosophy pursued throughout the Chosun Dynasty.

\section{DECORATION}

\subsection{Decorative pattern drawings}

There were two basic pattern drawings involved in the Chosun Buncheong ware as decorative methods; main pattern drawings and its accompanying pattern drawings. For a number of main patterns in Buncheong ware, the physical reality of a chosen subject, its visual characteristics, and what it signified as a main theme of the vessel, were modified, redefined and expressed in a lot simpler and more abstract way. Accompanying patterns were the stylized, schematic pattern designs usually derived from the main patterns employed. However, not all the Buncheong ware followed the same decorative structure. There were some exceptions such as Cheolhwa(underglaze iron-painted) Buncheong ware which, at times, showed no accompanying patterns drawn on the surface. Sometimes the main pattern design looked half-abstract or went further through such extreme changes and transforming process that it was hard to recognize what the original subject was at the beginning. Some popular subject matters for main patterns listed as follows; willow trees, chrysanthemum, lotus, a range of different scrolls or arabesques, peony, birds, fish, dragons, etc. As for the accompanying patterns, full bloomed lotus and chrysanthemum, all sorts of different scrolls, and highly schematic patterns including sacred fungus, waves, rain drops, Chinese fret, and etc.[6]

\subsection{Bunjang techniques}

There were two major differences in white slip application methods for Buncheong ware in the Chosun Dynasty; one with the entire covering or coating of vessels with Bunjang, and the other with detailed decorating processes involved after the whole covering of vessels were done. These two applications were divided into seven Bunjang techniques used in the decoration process of Buncheong ware.

a) Sanggam(Inlaid)
Sanggam was the unique pottery technique used in the Koryo Dynasty, the empire that had reigned over the country before Chosun Dynasty. The technique was handed down to the Chosun Dynasty, and was developed and flourished in its own right. There were two different Sanggam techniques; line-inlaid and surface inlaid. First, decorative motifs, designs or patterns were carved out on the surface and filling in the carved areas with white or black clay in greenware stage followed. In order to clarify the patterns and even out the surface, clay residue needed to be wiped out. The Koryo Sanggam technique often showed a tendency of displaying fine, sophisticated and detailed decoration whereas Chosun Sanggam technique showed wider, larger and more casual inlaid surface.

\section{b) Inhwa (Stamping)}

Inhwa technique was different kind of Sanggam technique involving continuous stamping of traditional motifs on the greenware, and filling in the pressed pattern with Bunjang. Once the white slip that lay on the pressed area was dried, the clay residue was wiped off, that the stamped or incised area was remained white.

\section{c) Bakji (Sgraffito or reversed inlay)}

The entire surface of a vessel was covered with white slip, and then desired patterns or designs were engraved on the surface. After that, the void areas were cut away to form the designs and patterns displaying strong contrast made from the cutout areas and the Bunjang designs or patterns.

\section{d) Umgak or Johwa (Incised technique)}

Umgak technique, also called Johwa, involved white slip application on the surface of a vessel using a brush, and then desired patterns or designs were carved out in lines. The beauty of Johwa Buncheong ware was often achieved by variation of lines with distinctive expressions.

\section{e) Cheolhwa (Underglaze iron- brown painting)}

Cheolhwa technique involved drawing or painting of designs using iron-rich pigments on vessels. Before painting, Bunjang, white slip needed to be applied on the entire surface of a vessel. The main feature of Cheolhwa was the powerful and energetic harmony of brown-black and white patterns or designs.

\section{f) Gwiyal (Brushed slip)}

"Gwiyal" technique was white slip application on the surface using a brush. Instant brush strokes were attempted to remark a sense of speed and energy. The intention of this particular technique sought for the natural and unintentional brush marks as patterns, often achieved from the strong contrast made with in-between-brush strokes of white slip and bare surface of the body. 


\section{g) Deombeong (Dipping)}

"Deombeong" basically means dipping vessels into white slip itself by holding its foot. Thus there were no brush marks, nor deliberate patterns on a surface. The rundown of white slip in the interior and sides of a vessel displayed highly abstract beauty of the Chosun Dynasty. Most vessels with Deombeong technique of Buncheong ware was often found at the late Buncheong ware stage.

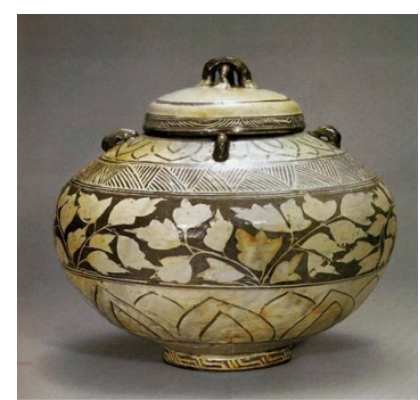

Fig. 8. Buncheong Sanggam(Inlaid) techniques

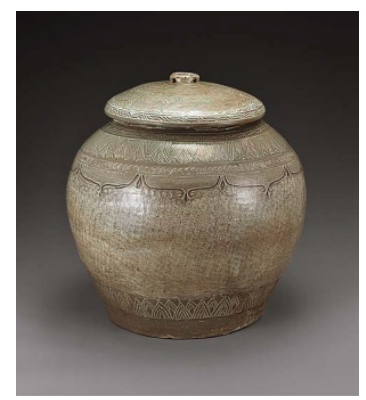

Fig. 9.. Buncheong Inhwa (Stamping) techniques

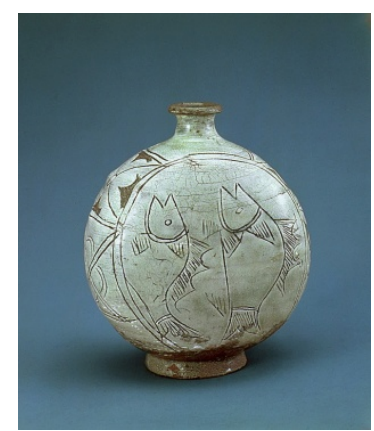

Fig. 10. Buncheong Bakji (Sgraffito or reversed inlay)

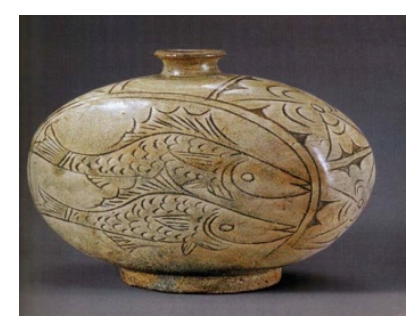

Fig. 11. Buncheong Umgak or Johwa (Incised technique)

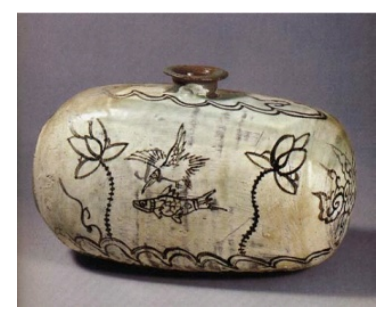

Fig. 12. Buncheong Cheolhwa (Underglaze iron- brown painting)

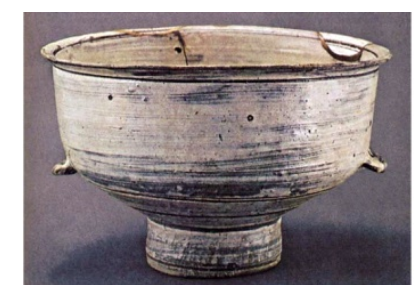

Fig. 13. Buncheong Gwiyal (Brushed slip)

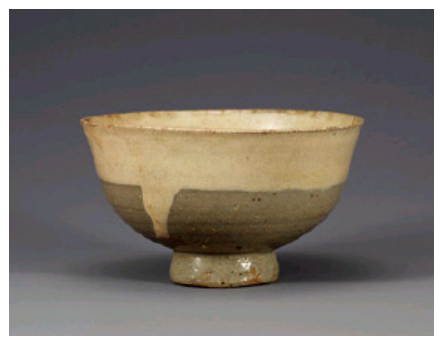

Fig. 14. Buncheong Gwiyal (Brushed slip)

\section{INGREDIENTS AND RAW MATERIAL: PROPORTION OF RAW MATERIALS}

7.1 Chemical compositions of Bunjang clay, white porcelain and Celadon porcelain ingredients

\begin{tabular}{|c|c|c|c|c|c|}
\hline Raw materials & $\mathrm{Sio}_{2}$ & $\mathrm{Al}_{2} \mathrm{O}_{3}$ & $\mathrm{Fe} 2 \mathrm{o} 3$ & $\mathrm{TiO}_{2}$ & $\mathrm{CaO}$ \\
\hline Hong Kong Clay & 95.9 & 33.6 & 1.38 & 0.3 & 0.26 \\
\hline gairome clay & 49.9 & 34.65 & 1.33 & 0.83 & 0.22 \\
\hline (Gaya) Kaolin & 46.6 & 37.4 & 0.73 & 0.15 & 1.07 \\
\hline (Hadong) Kaolin & 43.02 & 39.85 & 0.95 & - & 0.7 \\
\hline $\begin{array}{c}\text { (Go Heung) } \\
\text { pottery stone }\end{array}$ & 77.5 & 15.9 & 0.64 & 0.1 & 0.11 \\
\hline (Gim chon) Flint & 98.9 & 0.3 & $\operatorname{tr}$ & $\operatorname{tr}$ & - \\
\hline $\begin{array}{c}\text { (Dong myung) } \\
\text { Flint }\end{array}$ & 97 & 1.44 & - & - & - \\
\hline $\begin{array}{c}\text { (An-dong) } \\
\text { Feldspar }\end{array}$ & 68.36 & 15.56 & 0.22 & 0.08 & - \\
\hline $\begin{array}{c}\text { (Young-san) } \\
\text { Clay }\end{array}$ & 61.44 & 21.78 & 2.47 & - & 0.53 \\
\hline $\begin{array}{c}\text { (An-yang) } \\
\text { Feldspar }\end{array}$ & 67.02 & 20.86 & 0.09 & - & 0.31 \\
\hline $\begin{array}{c}\text { (Chung-ju) } \\
\text { Limestone }\end{array}$ & 0.47 & 0.13 & 0.11 & - & 55.58 \\
\hline \begin{tabular}{c} 
Gairome clay \\
\hline
\end{tabular} & 48.9 & 34.1 & 1.33 & - & 0.22 \\
\hline
\end{tabular}

\begin{tabular}{|c|c|c|c|c|}
\hline Raw m;aterials & $\mathrm{MgO}$ & $\mathrm{K}_{2} \mathrm{O}$ & $\mathrm{Na}_{2} \mathrm{O}$ & Ig.loss \\
\hline Hong Kong Clay & 0.24 & 0.6 & 0.13 & 17.67 \\
\hline gairome clay & 0.24 & 0.69 & 0.09 & 12.83 \\
\hline (Gaya) Kaolin & 0.22 & 0.82 & 1.57 & 11.4 \\
\hline (Hadong) Kaolin & - & - & - & 14.78 \\
\hline (Go Heung) & 0.16 & 3.18 & 0.16 & 2.25 \\
\hline
\end{tabular}




\begin{tabular}{|c|c|c|c|c|} 
pottery stone & & & & \\
\hline (Gim chon) Flint & 0.1 & - & 0.9 & 0.3 \\
\hline $\begin{array}{c}\text { (Dong myung) } \\
\text { Flint }\end{array}$ & - & - & - & 1.56 \\
\hline $\begin{array}{c}\text { (An-dong) } \\
\text { Feldspar }\end{array}$ & - & 8.64 & 6.23 & 0.91 \\
\hline $\begin{array}{c}\text { (Young-san) } \\
\text { Clay }\end{array}$ & 0.7 & 1.96 & 0.5 & 10.54 \\
\hline $\begin{array}{c}\text { (An-yang) } \\
\text { Feldspar }\end{array}$ & 0.15 & 2.22 & 7.57 & 1.06 \\
\hline $\begin{array}{c}\text { (Chung-ju) } \\
\text { Limestone }\end{array}$ & 0.13 & - & - & 43.42 \\
\hline Gairome clay & 0.24 & 0.69 & 0.09 & 13.71 \\
\hline
\end{tabular}

\subsection{Proportion of Bunjang ingredient (White engobe or slip)}

\begin{tabular}{|c|c|c|c|c|c|c|}
\hline $\begin{array}{c}\text { Name of } \\
\text { Ingredie } \\
\text { nts }\end{array}$ & Feldspar & $\begin{array}{c}\text { Flint } \\
\text { (Silica } \\
\text { or } \\
\text { Quartz) }\end{array}$ & $\begin{array}{c}\text { Kaoli } \\
\mathrm{n}\end{array}$ & $\begin{array}{c}\text { Gairome } \\
\text { clay }\end{array}$ & Alumina & $\begin{array}{c}\text { zircon } \\
\text { ium } \\
\text { silicat } \\
\mathrm{e}\end{array}$ \\
\hline $\begin{array}{c}\text { Formula } \\
1\end{array}$ & 15 & 25 & 25 & 25 & 6 & 4 \\
\hline $\begin{array}{c}\text { Formula } \\
2\end{array}$ & 35 & 30 & 35 & & \\
\hline $\begin{array}{c}\text { Formula } \\
3\end{array}$ & 15 & 30 & 30 & 15 & 5 & 5 \\
\hline $\begin{array}{c}\text { Formula } \\
4\end{array}$ & & 40 & & 30 & & 30 \\
\hline $\begin{array}{c}\text { Formula } \\
5\end{array}$ & & 40 & 40 & 20 & & \\
\hline
\end{tabular}

\section{CONCLUSIONS}

White slip technique using engobe has been the most widelyused decoration technique across the world. In Korea, a variety of White slip techniques were used, mainly for grayish-bluepowered celadons.

Traditional Bunjang technique used for Bunchong ware has big impact on modern ceramic art such as Beginning, pattern, form, composition, etc.

Modern ceramic art has gone beyond the traditional pottery, expressing more artistic values by the medium of earth as well as presenting unique features of individual artists instead of simply following the tradition. Furthermore, as ceramic artists are developing new white slip techniques, base on the traditional ones, artistic expression in ceramic art is going more and more diverse.

Bunjang in modern ceramic art is used traditional or the application techniques used to create the new techniques for work. If artist fully study and understand value of traditional Bujang technique, it can be to take advantage of unique decorative techniques to create a new ceramic works.

Furthermore, as ceramic artists are developing new techniques, building on the traditional ones, artistic expression in ceramic art is going more and more diverse.

\section{REFERENCES}

[1] K. S. Gang, The research of grayish-blue-powdered celadon, Iljisa, Korea, 1986

[2] D. K. Gang and Y. W. Kim, Rediscovery of Korea art (9) Ceramic Art, Solbook, Korea, 2004
[3] Y. S. Go, The first draft of aesthetic analysis of Korea art history, Tongmunkwan, Korea, 1963

[4] Y. M. Jung, The pottery of Korea, Moonye Publisher, Korea, 1991

[5] H. S. Lee and P. Y. Kim, Glaze and basic material of glaze, Daekwangbook, Korea,1988

[6] Y. J. Lim, The history of Korea pattern, Mijinsa, Korea, 1983

[7] J. Y. Kim, Korean Art Book-White Porcelain and Punchong Ware, Yekyong, Korea, 2000

[8] Ewha Womans University Museum, Excavation report of the Joseon white porcelain point at Gwangju, Korea, 1986

[9] S. H. Shin, movement of the modern ceramic art for the future, Hongik University research institute, Korea, 1993

[10] Y. M. Chung, G. Choi, Y. I. Yoon, J. H. Cho, The Story of Korean Ceramics, World Ceramic Exposition Foundation, Korea, 2004

[11] Y. I. Yoon, Study on the Establishment and Relocation of Royal Kilns during the Joseon Period 1,2: Ancient Art, Art History Association of Korea, Korea, 1981, pp.149151.

[12] Y. I. Yoon, Characteristic of Ceramics in the Early, Mid, and Late Joseon Period, Ancient Art, Spring/Summer/Autume, Korea, 1990

[13] K. Choi, Study on the Requirements for the Production of Bunchongware, Cultural Properties vol. 21., Research Institute of the Cultural Properties Administration, Korea, 1988

[14] J. Y. Kim, Essay on Bunchengwear: Masterpiceces of Buncheong Ware, Collection of Ho-Am Art Museum, Ho-Am Art Museum, Korea, 1993

[15] D. B. Park, Study on Firing of Ceramics during the Joseon Period, Cultural Properties vol. 11. Seoul, Research Institude of the Cultural Properties Administration, Korea, 1977

[16] M. N. Choi, Bunchengwear Kiln Sites in Cheonghang-ri, Korean Anthropology Vol. 1.Seoul: Department of Archeology and Anthropology, Seoul National University, Korea, 1967

[17] A. R. Lee, Instroduction to the New Collection of the National Museum of Korea Bunchengwear Bowl with Stamped Design: Museum Newspaper 278, National Museum of Korea, Korea, 1994

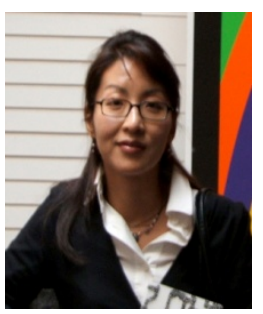

\section{Hae Jin Kim}

HaeJin Kim received the B.F.A., M.F.A. in ceramic Art from Ewha Womans University, Korea in 1993, 2005 respectively and also attending Ph.D. program in Apply Art at Hanyang University, Korea. Currently, HaeJin Kim is a Professor of Ceramic Design in the Department of Crafts Design at Kongju National University in Korea. 


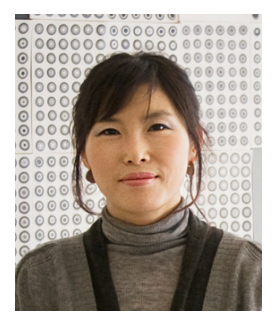

\section{Hae Sin Ro}

HaeSin Ro received the B.F.A., M.F.A. in Ceramic Art from Ewha Womans University, Korea in 1988, 1990 respectively. Since then, she has been with Kongju National University, Korea as a professor. HaeSin Ro's work is in numerous collections in the world, include Victoria and Albert Museum.

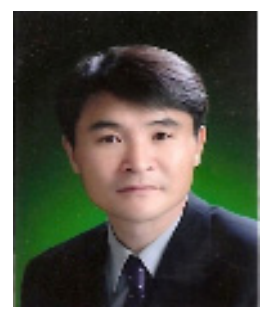

\section{Won Seok Kim}

WonSeok Kim received the B.F.A. in Ceramic Art from Mokwon University, Korea in 1984. The M.F.A. in Ceramic Art from Hongik University, Korea in 1987. Since then, he has been with Kongju National University, Korea as a professor. Kumkang Art Center president. 